\section{Clearance of severe psoriasis after allogenic bone marrow transplantation}

\author{
D J Eedy, D Burrows, J M Bridges, F G C Jones
}

Department of

Dermatology, Royal

Victoria Hospital, Belfast

BT12 6BA

D J Eedy, MRCP, senior

registrar

D Burrows, FRCP, consultant

dermatologist

\section{Department of}

Haematology, Royal

Victoria Hospital, Belfast

BT12 6BA

J M Bridges, FRCP, professor

of haematolog $\nu$

F G C Jones, MRCP,

consultant haematologist

Correspondence to:

Dr Eedy.

Br.Med $\mathcal{F} 1990 ; 300: 908$

South Glamorgan

Ambulance Headquarters, Fairwater, Cardiff

CF5 3XP

Clive Weston, MRCP, research registrar

\section{University Hospital of}

Wales, Heath Park, Cardiff

Michael Stephens, MD,

consultant cardiologist

Correspondence to: Dr Weston.
We describe here a patient with a 20 year history of severe intractable psoriasis which cleared completely after a bone marrow transplant. The case suggests a role for marrow derived $T$ cells in the pathogenesis of psoriasis.

\section{Case report}

A 36 year old white man had a 20 year history of severe intractable psoriasis that required numerous admissions to hospital for inpatient treatment. He had long periods of erythrodermic psoriasis and underwent many forms of treatment, including psoralens and ultraviolet $\mathrm{A}$, methotrexate, razoxane, and etretinate, in an attempt to control his psoriasis. In November 1984 he developed acute myelomonocytic leukaemia; remission was speedily induced using combined chemotherapy with cytarabine, daunorubicin, and thioguanine. His leukaemia remitted, but he continued to suffer severe psoriasis requiring treatment with methotrexate.

In August 1985 he was conditioned for an allogenic bone marrow transplant with cyclophosphamide $60 \mathrm{mg} / \mathrm{kg}$ twice and total body irradiation with $14 \mathrm{~Gy}$ given in seven fractions. He received a bone marrow transplant from his brother, who did not suffer from psoriasis. The bone marrow $\mathrm{T}$ cells in this transplant were depleted using monoclonal antibodies MBG6 and RFT8, and depletion was greater than $99 \%$. Immediately after the bone marrow transplantation his psoriasis disappeared entirely, and he remained free of it despite cessation of cytotoxic and immunosuppressive therapy.

In October 1986 he suffered a relapse of acute myelomonocytic leukaemia. He received a further bone marrow transplant from his brother (this time without depletion of $\mathrm{T}$ cells) without induction of remission after chemotherapy with cytarabine and cyclophosphamide. He received cyclosporin at a dose of $400 \mathrm{mg} /$ day after the transplant; the dose was tapered gradually and stopped after 10 months.

Since the initial bone marrow transplant he has remained completely free of psoriasis, and he has had

\section{Hypoglycaemic attacks treated by ambulance personnel with extended training}

\section{Clive Weston, Michael Stephens}

Hypoglycaemia is a common and potentially serious medical emergency. It occurs almost invariably as a complication of treatment with insulin or occasionally sulphonylureas. Patients often treat mild attacks at home, but more severe attacks warrant attending hospital or a visit by a general practitioner.

Our ambulance personnel are instructed how to measure capillary blood glucose concentrations (BM test, Boehringer Mannheim Ltd) and give a $50 \%$ dextrose infusion intravenously when oral glucose no further relapse of his myelomonocytic leukaemia. DNA typing performed on peripheral lymphocvtes confirmed chimerism, with the DNA type being that of donor.

\section{Comment}

There is growing evidence for the role of cellular immunity in the pathogenesis of psoriasis. One of the earliest histological findings in psoriasis is that of a lymphocytic infiltrate in the dermis, mainly comprising the T helper subtype. ' 2 Studies of circulating lymphocyte subpopulations in psoriasis have yielded conflicting findings, with decreased numbers of $T$ helper cells ${ }^{2}$ or $\mathrm{T}$ suppressor cells $\mathrm{s}^{3}$ or no abnormality being reported.

Our patient has remained free of psoriasis for some four years and, in the absence of immunosuppressive or other treatment, this seems to indicate that a change in a patient's cellular immunity may bring about long lasting remission of psoriasis, even in a severe case. The importance of this case is that it suggests that eradication of a patient's bone marrow derived immune system and its replacement with a genetically different one can bring about a total remission of severe psoriasis. This points directly to a central role for marrow derived lymphocytes in the pathogenesis of psoriasis. This case reinforces the importance of investigating further the genetic and cell mediated mechanisms that are likely to be important in the pathogenesis of psoriasis. Furthermore, it explains the mechanism whereby selective immunosuppressive drugs, such as cyclosporin $\mathrm{A}$, may work in psoriasis and suggests that further efforts to achieve drug treatment of psoriasis might centre on immunomodulation.

We thank Dr A K Burnett, Glasgow Royal Infirmary, who performed the first bone marrow transplant.

1 Bos JD, Hulsebosch HJ, Krieg SR, et al. Immunocompetent cells in psoriasis. In situ immunophenotyping by monoclonal antibodies. Arch Dermatol Res 1983;275:181-9.

2 Baker BS, Swain AF, Naldimasson H, Fry L. T cell subpopulations in the blood and skin of patients with psoriasis. Br f Dermatol 1984:110:37-44.

3 Gladmann DD, Keystone EC, Russell ML, Schachter RK. Impaired antigenspecific suppressor cell activity in psoriasis and psoriatic arthritis. $f$ Invest specific suppressor cell

4 De Pietro WP, Berger CL, Herber LC, Edelson RL. Normal numbers of phenotypic helper, suppressor, and total $T$ cell populations in psoriasis vulgaris: Quantitation by monoclonal antibodies. F Am Acad Dermatol $1981 ; 5: 304-7$.

Griffiths CEM, Powles AV, Leonard JN, et al. Clearance of psoriasis with low dose cyclosporin. Br.Med f 1986;293:731-2.

(Accepted 2 February 1990) cannot be given. We investigated their role in managing hypoglycaemic attacks.

\section{Methods and results}

At the beginning of 1988 there were 14 ambulancemen and women with full extended training. ${ }^{.}$For 12 months beginning on 1 January 1988 all report forms from these crews were studied for cases of hypoglycaemia. Treatment at the scene, patients' responses to treatment, and the final outcomes of the crews' intervention were recorded. We also studied casualty department cards and inpatient notes.

Ambulance personnel attended 35 episodes of hypoglycaemia affecting 31 patients (19 men) (table). One patient did not have diabetes but had taken an overdose of insulin; four patients were non-insulin dependent diabetics; the remainder were taking insulin. The capillary blood glucose concentration before treatment 